\title{
Eco-technologies for energy efficient buildings in Italy
}

\author{
A. Boeri \& D. Longo \\ University of Bologna, Department of Architecture and Territorial \\ Planning, Faculty of Architecture, "Aldo Rossi", Italy
}

\begin{abstract}
The climatic context has an essential role in the building construction strategy: it represents the main benchmark to define criteria for energy-efficient buildings design. The control of external conditions through the building envelopment is essential for energy saving.

Environmental protection and energy saving characterize some strategic European experiences. Lots of European countries are promoting and sharing a sustainable building approach to be in compliance with the Kyoto Protocol and subsequent international agreements, such as those established at the last Copenhagen climate conference.

Assuming that buildings have a high environmental impact, in terms of energy and resources consumed, it is necessary to adopt different criteria in relation to climate zones. The design strategies in terms of new constructions and upgrading of existing buildings are based on the concept that building is a composite system, where the architecture, the layout of fronts and openings, the performances of the building shell and integration with the fixtures and fittings, also powered by renewable sources, must be efficiently balanced.

The Passivhaus standard, which defines low energy buildings with heating not dependent on fossil fuel, was originally developed in central European countries and recently it has been revised to adapt its criteria to different climate contexts, especially those of the Mediterranean.

In warm areas the energy efficiency is related to summer performances and passive cooling of buildings. Significant experiences are developing even in Italy, where the Mediterranean climate has different characteristics compared to the cold climates of central and northern Europe.
\end{abstract}


Italian regions have more differentiated climates: according to the seasons, protection from summer heat and energy containment during the winter have differing levels of importance. In southern and central Italy the main factor is the heat control in the summer period, during which situations of overheating which imply relevant energy consumption due to conditioning systems - shall be limited. It is possible that the energy required to cool the buildings exceeds the requirements for heating.

Keywords: ecology, energy efficiency, technology, passive house, Mediterranean architecture.

\section{Introduction}

The design strategy for energy-efficient buildings is based on climate analysis, the main benchmark to define criteria design. The Italian climatic context has predominantly Mediterranean characteristics, which differ from the cold climates of central and northern Europe, where major researches and applications concerning the containment of energy in buildings were conducted. In countries that have developed lots of experiences, such as Germany, Austria, Switzerland and the Scandinavian countries, the researches on energy efficiency and the concept of passive building refer to contexts characterized by harsh winters where the priority is the containment of the heat dispersion - and summers with higher temperature conditions.

The buildings have mainly to ensure high levels of thermal insulation to contain the dispersion in the winter; the glazed surfaces should allow the

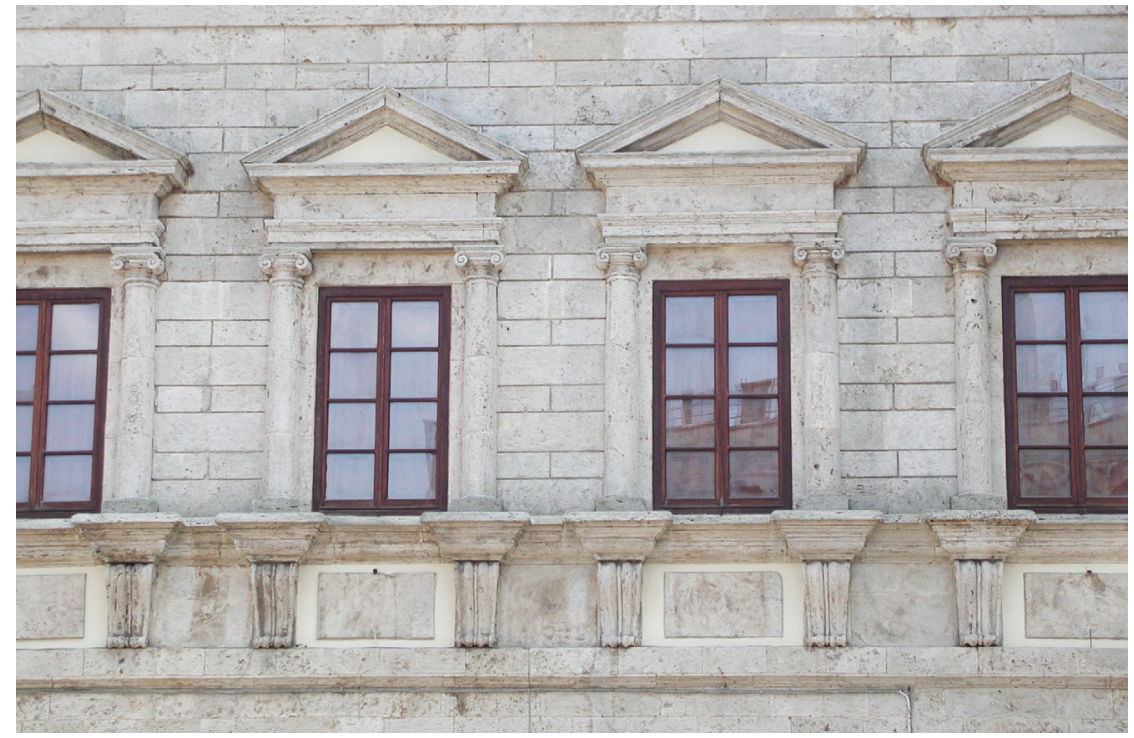

Figure 1: Historical building. The Italian traditional architecture is characterized by envelopes built with considerable mass materials. 
incoming of solar radiation, which is useful for lighting and passive heating of the interiors, keeping down the overall transmittance of the building shell.

In these contexts issues related to summer heat and to the presence of moisture, typical of many areas of Italy, are less important. Italian regions have more differentiated climates: according to the seasons protection from summer heat or the energy containment during the winter have different levels of importance. In the alternation of seasons the buildings have to answer to cold winters and hot summers, often with high humidity, and provide adequate performances in different conditions.

In southern and central Italy the main factor is the heat control that regards just the summer period, during which situations of over temperature condition that imply relevant energy consumption due to conditioning systems - shall be limited. It is possible that the energy required to cool the buildings exceeds the requirements for heating.

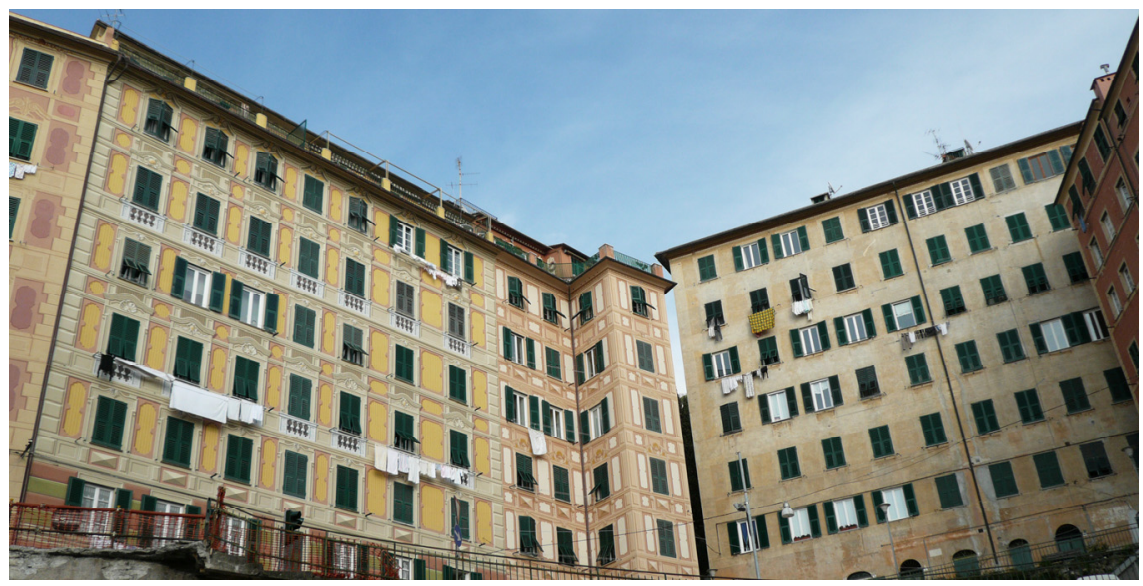

Figure 2: $\quad$ Typical buildings of the north-west Italian coast.

\section{The national context}

The Italian territory is characterized by different climates, variable from predominantly cold (Alpine) to warm (southern regions and islands), and areas with temperature variations related to significant seasonal cycles. The recent growing attention to the issue of buildings energy efficiency puts the stress on the technical and regulatory problems related to the search for solutions suitable for specific environmental conditions.

Therefore, it is necessary to define design solutions to respond to different climatic conditions, to contain energy consumption during the winter and to limit the interior over temperature during the summer. The main energy consumption in buildings regards the need of heating during the winter and/or cooling in the summer. 
The national decrees, transposition of European Directive 2002/91/EC, providing different limits for indicator of energy performance for the winter climate, expressed in $\mathrm{kWh} /$ year per unit of area or volume depending on the climatic zone of reference, apply an early diversification according to the weather conditions.

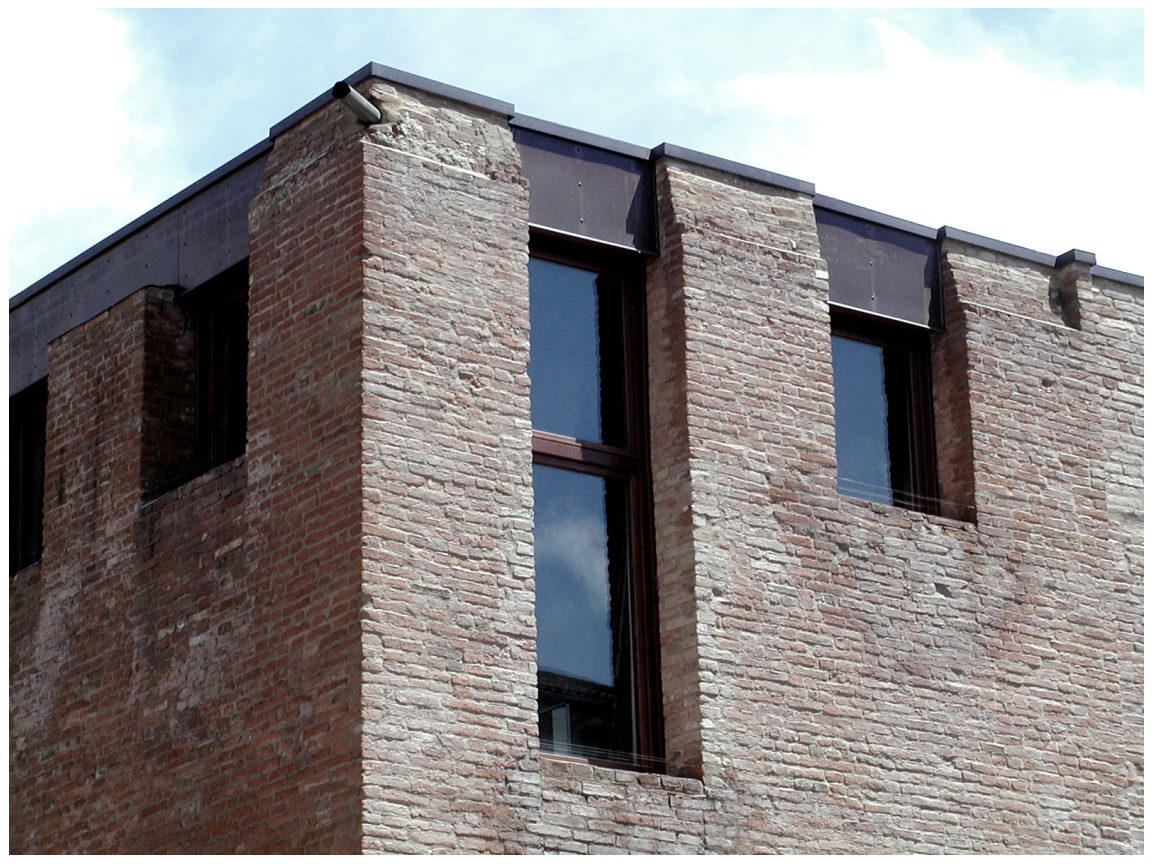

Figure 3: Energy upgrading works of a historical monumental building. Bologna.

\section{Guidelines for passive house}

Having briefly outlined the national state of the art, characterized by significant climatic differences that have correspondence in regulatory requirements, it is interesting to note how the concept of passive house, born in the colder climates of central Europe, is developing with adaptive criteria in other countries.

In particular the research project Passive-On, sponsored by the EU SAVE Intelligent Energy, which aims to promote the passive houses in warm climates, is very interesting.

The concept, developed first by Passivhaus Institute in Darmstadt, has been deepened by researches and trials in Europe, such as the CEPHEUS - Cost Efficient Passive Houses as European Standards project on the potentials of an alternative approach to the issue of energy use in buildings, designing solutions and suggesting technologies for buildings that can consume minimal amounts of energy during their life cycle, without increasing the cost of construction. 
The passive house consumes limited amount of energy for its management and doesn't use fossil fuels, using only minimal amounts of auxiliary energy: the original codification restricted the annual requirements for heating in not more than $15 \mathrm{kWh} / \mathrm{m}^{2}$ and the total of domestic consumption (hot water, cooling, lighting, appliances) not more than $42 \mathrm{kWh} / \mathrm{m}^{2}$.

Adapting the concept to the warmer climates it is necessary to take into account the specific needs for cooling, also using mechanical systems. Therefore the annual limits for heating were defined in $15 \mathrm{kWh} / \mathrm{m}^{2}, 15 \mathrm{kWh} / \mathrm{m}^{2}$ for cooling and $120 \mathrm{kWh} / \mathrm{m}^{2}$ for total primary energy for all consumption.

The experiments in progress on passive designing in hot climate, similar to what happened in cold climates, will be a reference to the development and application of more progressively efficient buildings.

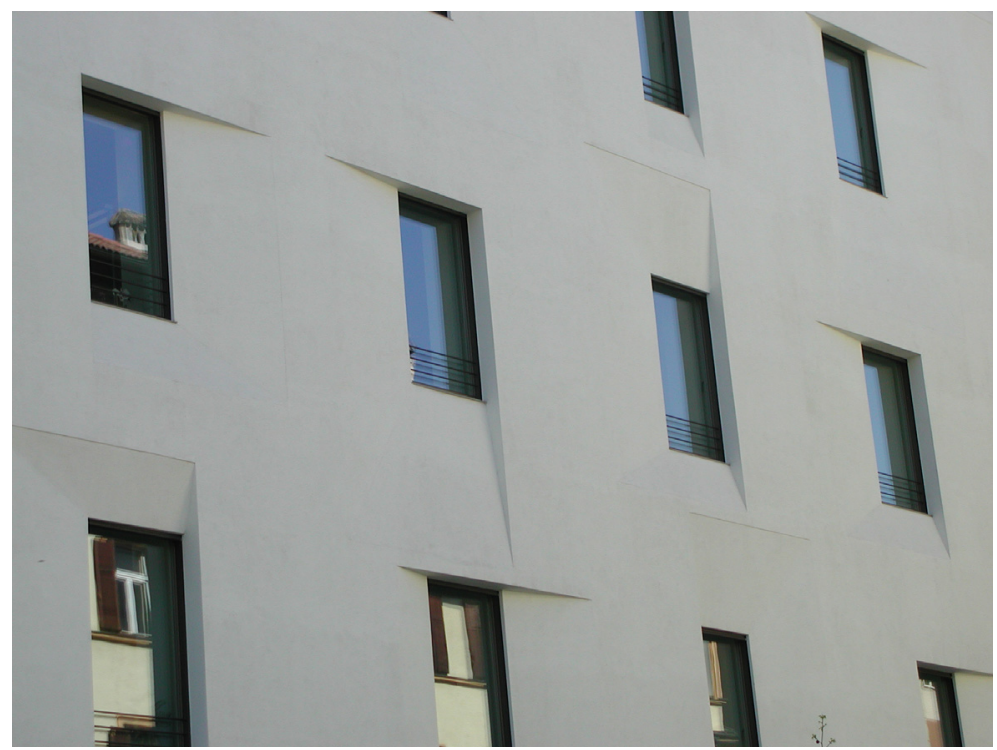

Figure 4: Energy retrofit of the new headquarters of the Autonomous Province of Bolzano. This is the first national public building with a consumption of only $12 \mathrm{kWh} / \mathrm{m}^{2}$ year for heating. It reaches the European standard of passive house.

\section{Design criteria}

The passive houses are characterized by design criteria focused on energy efficiency of the integrated building systems, pursing energy saving, minimizing the active fixtures and fittings, powered by energy.

Since the heat exchange between inside and outside carries out through the building envelope, it is important to use a compact building shell, and take advantage of opportunities to combine buildings, use a simple shell form, and minimize shaded areas in winter. It is fundamental the shape of the building and 
in particular the relationship between all dispersing surfaces and the heated or cooled volume. The passive standard provides that the limit of the $\mathrm{S} / \mathrm{V}$ ratio, that is to say the index of compactness (the same also provided by national legislation), is not greater than 0.6. Buildings characterized by a compact form and a considerable volume imply a minor thermal exchanges. This consideration is valid in general even in hot context. While increasing the dispersant surface, the building form has to favor the natural ventilation, necessary for cooling during the night.

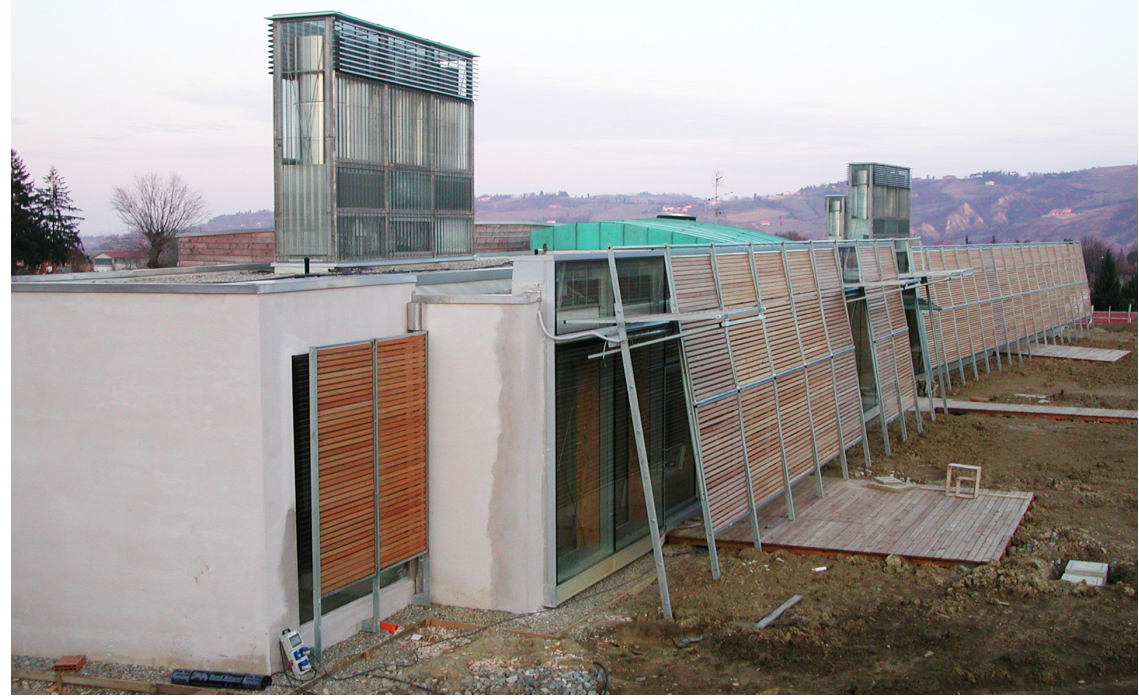

Figure 5: The design of the School of Children in Ponticelli, Imola is characterized by energy efficiency. The north facade is extremely compact; the south one is glazed and protected by a system of external shields. On the roof there are air extractors for summer free cooling.

There are several typological examples to refer, such as traditional "domus italic".

The continuity of the insulation layer and the quality of shell components have a dual purpose: to avoid the spread of heat during the winter and over temperature during the summer. In relation to climatic conditions these functions, generally integrated, are important. In countries of central Europe and north Italy characterized by a hard winter, the dispersion control during this period is important, while in the Mediterranean areas the summer performances of buildings must be controlled. So, the designer has to determine insulation thickness of building envelope and avoid heat bridges.

To keep to Passivhaus standard (U-factor that does not exceed $0.15 \mathrm{~W} /\left(\mathrm{m}^{2} \mathrm{~K}\right)$ the components of the shell must have an insulation thickness of about $25 \mathrm{~cm}$ on 
the vertical walls, even more on coverage. The solution of isolation on the outer side of the wall, like a coat, avoids heat bridges (the transmittance of linear thermal bridge must be less than $0.01 \mathrm{~W} / \mathrm{mK}$ ) and protects the thermal mass of the structure, allowing the regulation of indoor comfort.

To complete the building shell also glazed surfaces must be extremely efficient: in cold climates to achieve the required standard (less than $0.8 \mathrm{~W} / \mathrm{m}^{2} \mathrm{~K}$ ) it is important to use windows with thermal insulated frame and triple-glazing with inert gas (argon, krypton), special low emissivity glasses, very transparent. In warm climates it is possible to obtain adequate results with insulating glasses and high performance frames (transmittance: between 1 and $1.2 \mathrm{~W} / \mathrm{m}^{2} \mathrm{~K}$, depending on the layout and size of the glazed surface). It is always necessary that the windows are applied respecting the continuity of the insulation layer, which must protect the same frame.

In general, the strict limits of thermal transmittance of the building shell are sufficient, in cold climates, to ensure high performances. In warm climates the integrative role of thermal inertia of the shell components should be considered. It is ensure by the high mass material that maintain an appropriate delay time (more than 12 hours) and mitigate, according to the thermal resistance of the structure, the effects of the external changes of temperature on the indoor microclimate.

In order to reduce heat transmission through the shell, subjected to direct solar radiation, to the inside layers, is appropriate to use ventilated solutions for

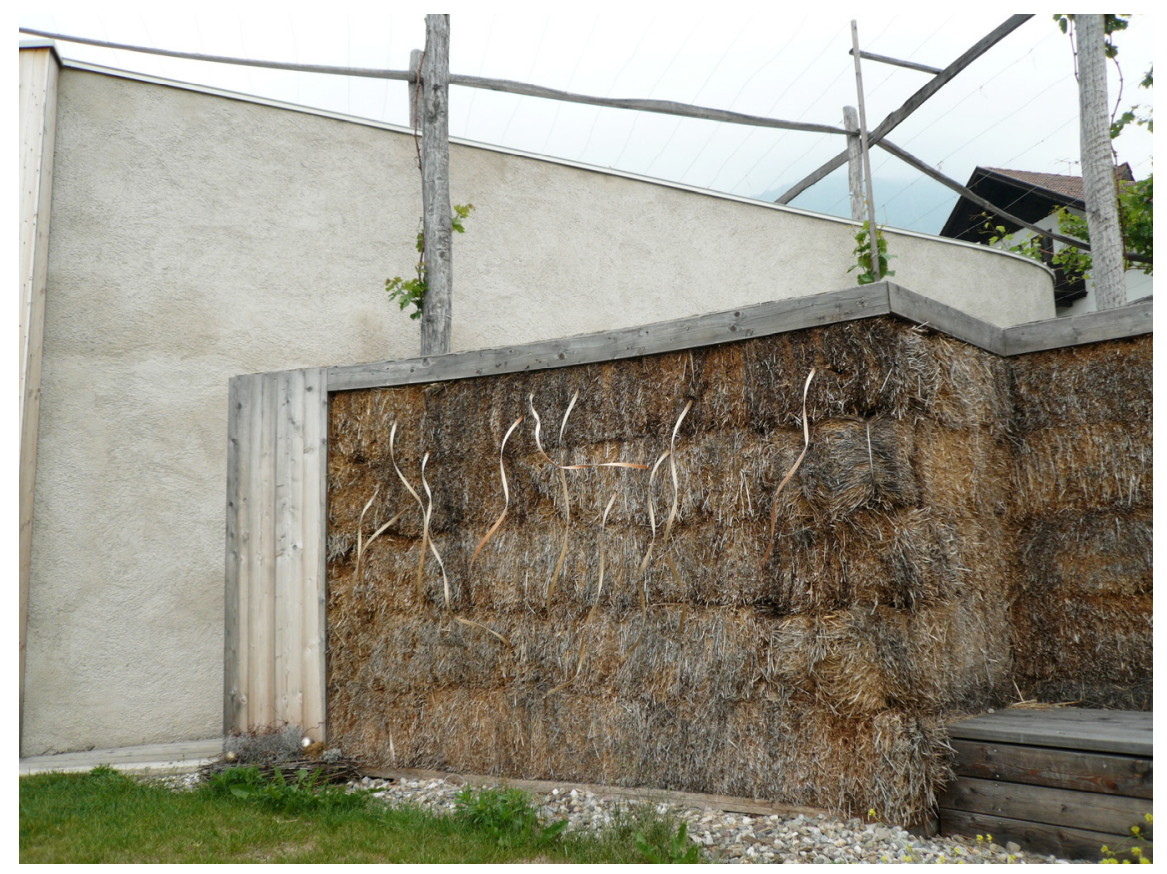

Figure 6: Wall construction sustainable system using straw bales. Hotel building as Passive house standard, Lana, Bolzano. 
the walls and especially the roofs, which are subjected to excessive sunshine in the summer.

The passive use of solar energy depends on the right position and orientation of the site. South orientation of the main side $\left( \pm 30^{\circ}\right)$, and large south-facing window areas are important. South exposure is the most favorable as it receives the maximum sunlight in winter, when the sun is low in the sky and its energy contribution is significant ( $44^{\circ}$ North Latitude, December 21th: the sun in high about $23^{\circ}$ above the horizon). Instead in the summer when the solar energy is unfavorable because it tends to generate over temperature inside, the sun is high in the sky (June 21: about $70^{\circ}$ above the horizon) and its beams hit on the vertical walls with high inclination. Therefore the facades are more protected from direct exposure.

However, since the exposure factors depend on conditions of the context the design criteria to define the size and orientation of the glazed surfaces should be defined with relation to the specific sites, regulating the conditions of solar capture.

South orientation of the main side receives the maximum radiation in winter, when the solar incidence is favorable, and a minor contribution in the summer. The experience has shown that on the south side the percentage of glazed surfaces in passive traditional buildings should not exceed $40 \%$ of the total facades, to limit the excessive losses due to the energy transmission. In warmer areas this value is to be significantly reduced depending on latitude, limiting glazed surfaces to $30 \%$ of the same façade. The exposure to solar radiation should be controlled by external shade elements. Particular attention should be pain at west windows, which contribute significantly to global over temperature. The north side, little sunny and exposed to cold winds, must be

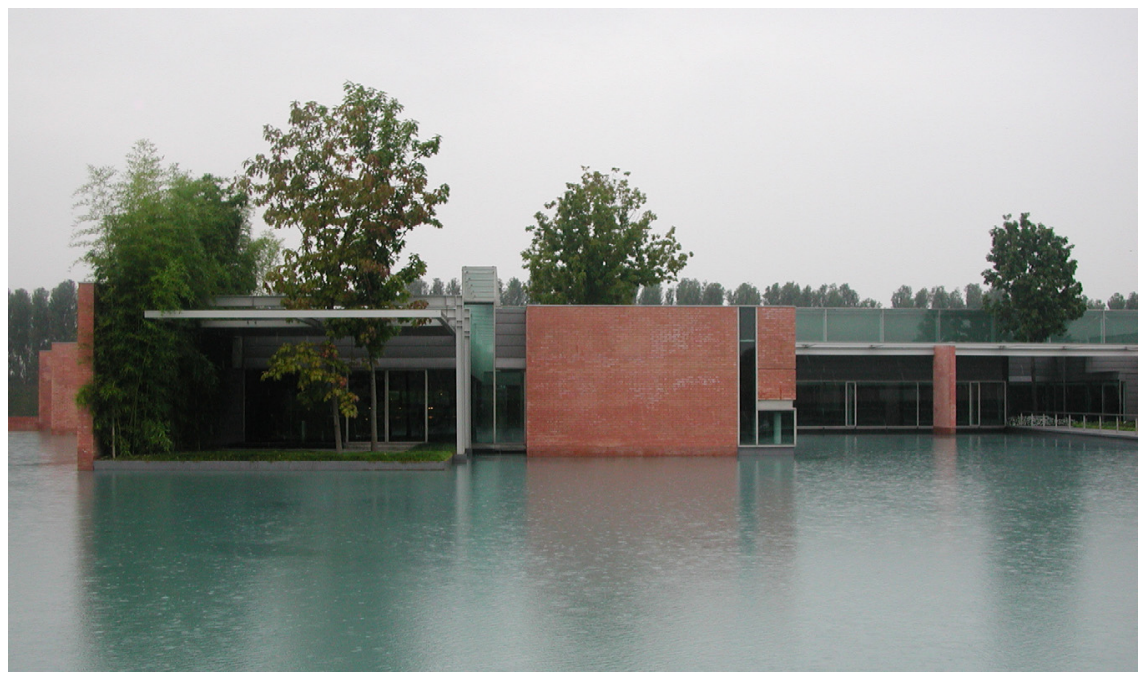

Figure 7: Integration of the building with artificial basin of water, Parma. The presence of water helps to reduce the high temperature in summer. 
closed as possible to avoid the dispersion of heat. It is important to use a building footprint that concentrates utility installation zones (e.g. bathrooms or kitchens and each other) or filter areas in this side.

To prevent heat loss and infiltration through the building envelope it is necessary to drastically reduce its permeability. Passivhaus standard requires a value of waterproof less than 0.6 volumes/hour of air chance measured with a pressure difference of $50 \mathrm{~Pa}$ between inside and outside. This is a very small value: in light dry constructive solutions is possible to apply a waterproof layer under the thermal insulation; for masonry solutions is important to require the continuity of plaster. Great care should be taken to assure that insulation layers are continuous, and without air pockets, to eliminate any discontinuity of different elements of the shell (it is important to have a building shell pressure test performed).

In warm climate areas the infiltration, even if negative, has less impact on energy loss, and the value of permeability can be increased to 1 volume/hour.

A passive house is a building in which a comfortable interior climate can be maintained without active heating and cooling systems (Adamson 1987 and Feist 1988). The house heats and cools itself, hence "passive". Low energy consumption to maintain the conditions of comfort is ensured by highly efficient heat recovery from exhaust air using an air-to-air heat exchanger. The mechanical ventilation has a dual function: on the one hand contributes to heat and cool the interiors, on the other allows their ventilation, necessary for the

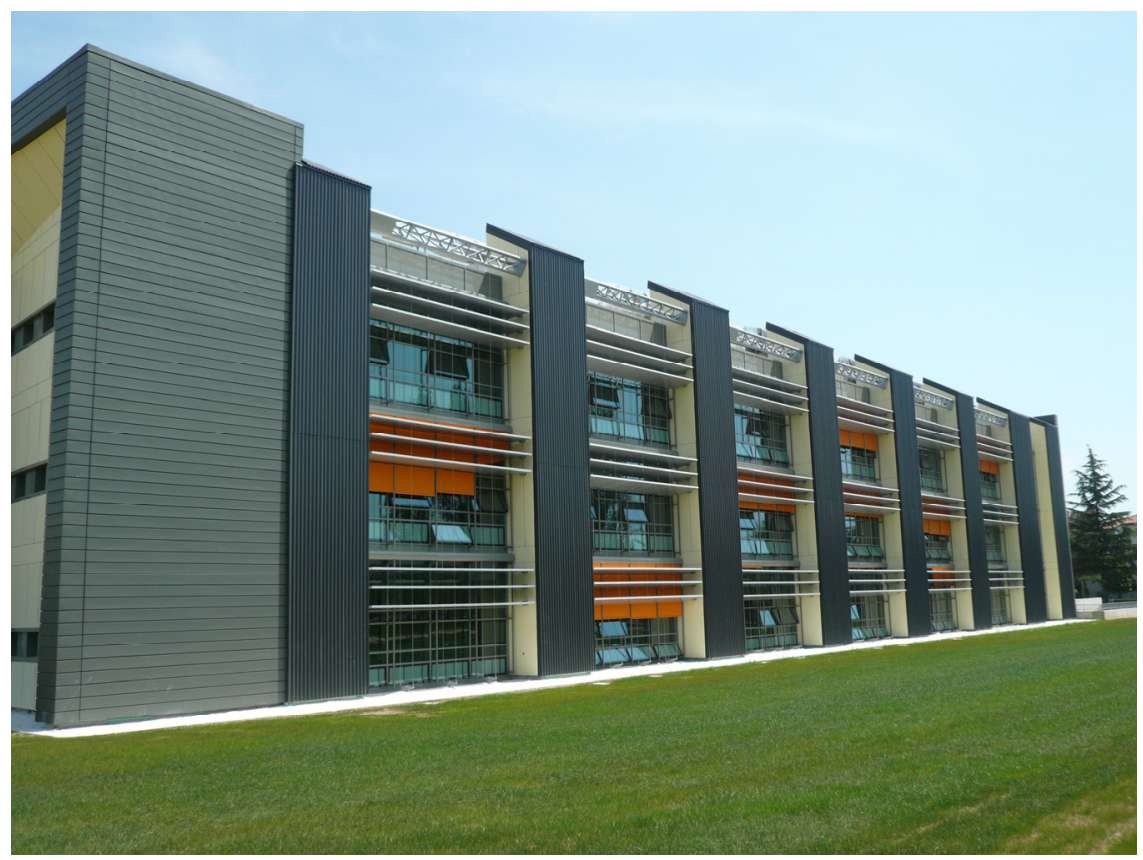

Figure 8: Low energy school in Imola. The plant system integrates solar wall, geothermal resources, solar cooling, etc. 
comfort indoor, avoiding the heat loss due to opening windows, providing an air supply of 30-40 mc/h per person.

Solar collectors or heat pumps are used for water heating. In warm climate the production with solar collectors is also sufficient for the winter: you can also integrate the collector to the heating system, providing auxiliary heat to it. Generally the collectors are placed on the coverage, but the tendency foresees to integrate them into the building envelope components.

The electricity needed for lighting, home consumptions and for ventilation fixtures are extremely low: it is important to use light sources and low energy consumption equipment.

The installation of a photovoltaic system capable of transforming solar energy into DC (direct current) may contribute to the energy production: any unused energy quantity can be accounted for and placed in the network of distributors.

In summary the project strategy for buildings passive control in hot climates tends to minimize the internal and external heat gains and obtain appropriate levels of time lag and reduction.

All the strategies related to the removal of the summer heat are to be appreciated. If the waterproof of the envelope avoids accidental infiltration which has a negative impact to the heat and energy balance, the exploitation of climatic context conditions in the appropriate seasons may cause considerable

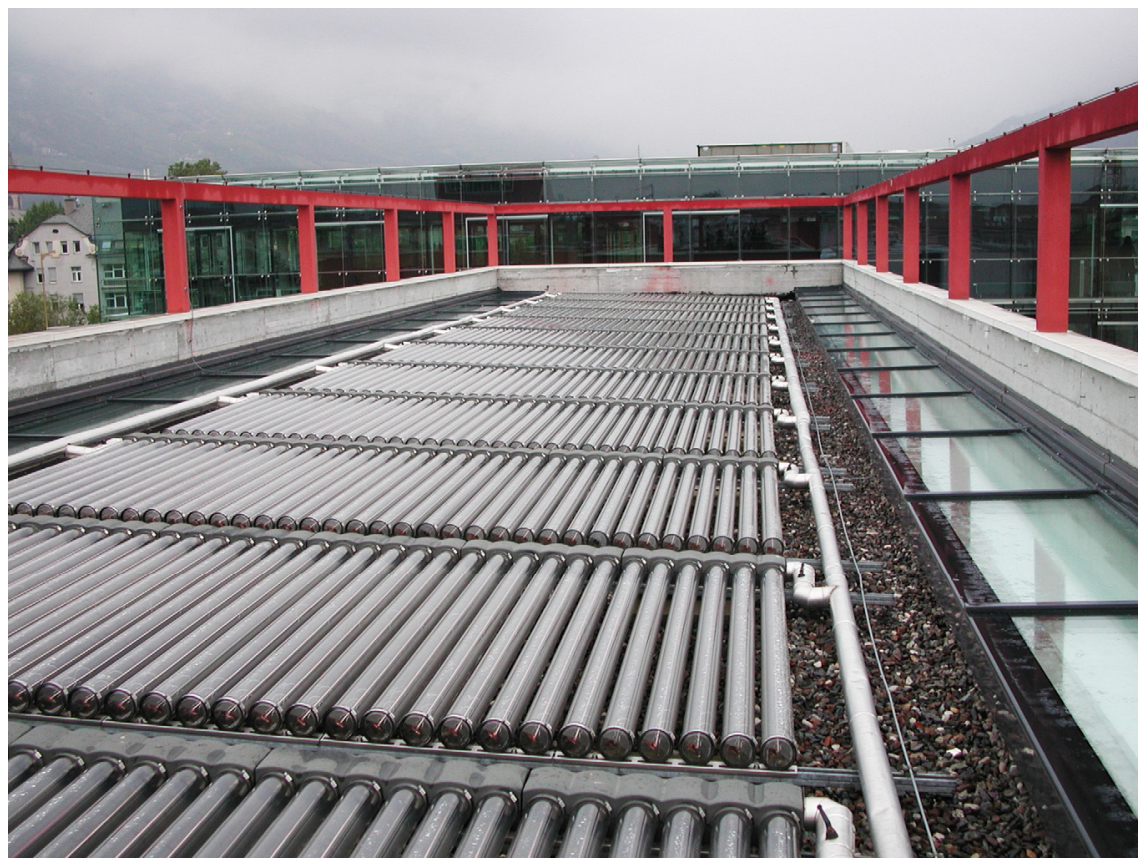

Figure 9: Solar collectors system on the roof. It needs hot water and heating. In the summer it contributes to air conditioning inside the building. 
free benefit of charge, contributing to the reduction of inside moisture. In particular the use of night ventilation, where the outside temperature falls to levels lower than that of comfort, can help to cool the thermal mass of the building, consisting of the massive structures in contact with the indoor environment, particularly if they are protected by insulation layer. This benefit helps to reduce high temperature during the following day. Alternative or supplementary forms consist of evaporative and geothermal cooling.

\section{The importance of the mass for over temperature control}

If the recent researches are primarily aimed to codify appropriate construction technologies for the energy saving in winter, it seems appropriate to focus attention on climate characteristics and in particular on the passive protection from the summer heat.
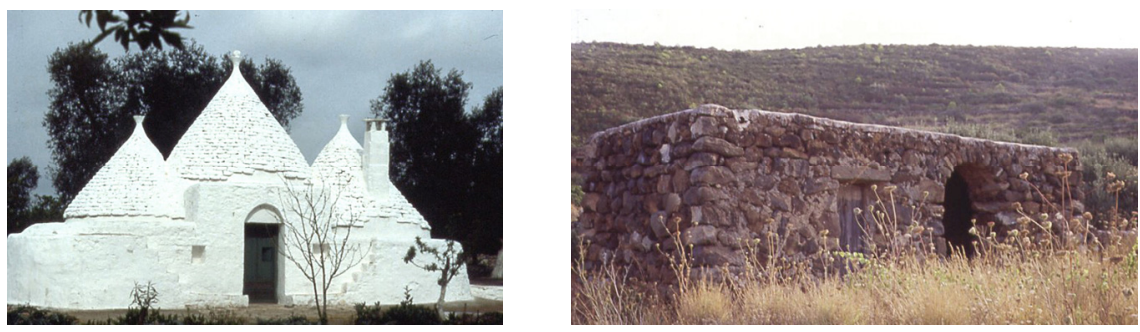

Figure 10: Traditional building typologies, "Dammusi" of Pantelleria and Apulian "trulli". The use of appropriate materials and the bioclimatic relationship with the context contribute to maintain a constant internal microclimate without integration systems.

To increase the heat capacity of building technological layers, you can use insulation with higher thermal mass, such as panels of wood fiber (with a density ranging from 130 to $190 \mathrm{~kg} / \mathrm{m}^{3}$ ), with very good hygroscopic performances. In general, lightweight solutions have not a considerable heat capacity, that is to say that they don't contribute sufficiently to delay the transmission of external thermal variations.

If the heat insulation is the most important and codified factor from the prescriptive point of view, in relation to different climates, in particular the warm ones, the role of thermal inertia of the building system gradually assumes importance. It is simple to define the concept but difficult to calculate this factor: at a glance it can be defined as the combined effect of the capacity of accumulation and heat resistance of the structure.

Traditional Italian architectures such as the Apulia "trulli" and "dammusi" of Pantelleria can represent simple but interesting bioclimatic reference models: they are able to maintain sufficiently constant temperature indoor, even without auxiliary fixtures and fittings, thanks to a correct architectural form, exposure, 
the relationship with the soil, and in particular to the thickness and mass of the envelope.

The coefficient of thermal lag allows evaluating the delay of transmission of the external thermal gradient changes inside. To obtain sufficient comfort conditions, lag should not be less than 8 hours, while optimal conditions are achieved with just 12 hours.

Therefore, especially in the summer, in addition to the transmittance it is important to assess the contribution of the massive materials, with higher heat capacity in order to reduce the effects of external thermal variations on the microclimate indoor.

\section{Conclusion}

The role of heat inertia, although extremely important in the characterization of energy efficiency of buildings in summer, cannot leave aside a more general design strategy aimed to a correct relationship with the environment. Among the main parameters the most important are the location, the shape and orientation of the building: southern orientation and shade considerations are some of the basic features that distinguish passive house construction. The ratio of dispersing surfaces and volume is an index of energy efficiency and it is considered a reference for regulations.

Other features of a passive house consist of an opportune distribution of rooms and functions, construction typology, use of energy-efficient window glazing and frames, application of solar shields. Particular important is natural or mechanical ventilation system - which may play an important role in summer cooling, encouraging the air change in the night (most of the perceptible heat in the exhaust air is transferred to the incoming fresh air) - and passive preheating of fresh air which may be brought into the house through underground ducts that exchange heat with the soil.

It is fundamental to integrate consciously energy-saving factors to realize buildings characterized by conditions of natural hydrothermal comfort with minimal energy use.

\section{References}

[1] AA.VV., Costruire sostenibile: il Mediterraneo (Cuore Mostra SAIE), Alinea: Firenze, 2001.

[2] AA.VV., +Qualità-Energia. Per costruire sostenibile, Be-ma: Milano 2008.

[3] Barucco, M.A., Trabucco, D., Architettura_Energia, Edicom: Montefalcone (Gorizia), 2007.

[4] Boeri, A., Criteri di progettazione ambientale, Delfino: Milano, 2007.

[5] Hendriks, Ch. F., Sustainable construction, Aeneas technical publishers: The Netherlands, 2001.

[6] Novi, F., La riqualificazione sostenibile, Alinea: Firenze, 1999.

[7] Smith, P., Eco-Refurbishment, Architectural Press: Oxford, 2004. 